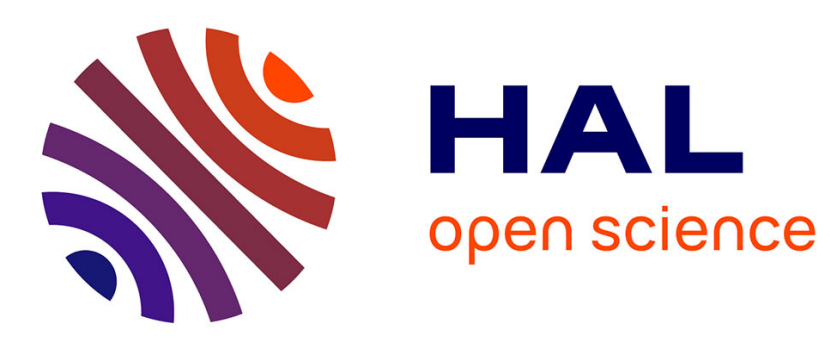

\title{
New approaches to plastic language: Prolegomena to a computer-aided approach to pictorial semiotics
}

\author{
Everardo Reyes-García, Göran Sonesson
}

\section{To cite this version:}

Everardo Reyes-García, Göran Sonesson. New approaches to plastic language: Prolegomena to a computer-aided approach to pictorial semiotics. Semiotica, 2019, 2019 (230), pp.71-96. 10.1515/sem2018-0106 . hal-02275018

\section{HAL Id: hal-02275018 \\ https://hal.science/hal-02275018}

Submitted on 21 Mar 2020

HAL is a multi-disciplinary open access archive for the deposit and dissemination of scientific research documents, whether they are published or not. The documents may come from teaching and research institutions in France or abroad, or from public or private research centers.
L'archive ouverte pluridisciplinaire HAL, est destinée au dépôt et à la diffusion de documents scientifiques de niveau recherche, publiés ou non, émanant des établissements d'enseignement et de recherche français ou étrangers, des laboratoires publics ou privés. 


\title{
New approaches to plastic language. Prolegomena to a computer-aided approach to pictorial semiotics
}

\author{
Everardo Reyes \\ Paragraphe Lab \\ Université Paris 8 \\ Göran Sonesson \\ Division of Cognitive Semiotics \\ Lund University
}

Pictorial semiotics, understood as the general study of pictures as signs, constituted a fundamental step beyond the art historical captivation with individual images. Particularly important in this respect was the division between the iconic (or, as we shall say, pictorial) and plastic layers of the picture proposed by Jean-Marie Floch and by Groupe $\mu$. Unlike Groupe $\mu$, whose interest lied mainly on figurative operations found in some pictures, Floch aimed at an exhaustive analysis of the pictures under study. Nevertheless, Sonesson observed some flaws in Floch's analysis: first, a model must be applied identically to several instances of the type modelled, in this case pictures in general or, alternatively, some particular kind of pictures, whereas Floch modified his model as his intuitive reading of the pictures changed. Second, it is not at all obvious that all pictures have to be organized by binary division. Third, the use of figurative pictures to derive the meaning of non-figurative ones must suppose the plastic layer to be completely redundant in relation to the pictorial one. If this is indeed the case, the division of the picture onto two different kinds of layers turns out to be futile.

The first part of this paper summarizes observations bridging the declared aspirations of pictorial semiotics and its real achievements. Since no other explicit model for the interpretation of pictures as pictures has been presented since the era of structuralism, we think that a critique of this model is still highly relevant. The second part of the paper offers some positive and on-going implementations designed to remedy the shortcomings observed. What is suggested in this second part could be taken as a proof of concept - the concept being that the requirements imposed by structuralism cannot be fully implemented by a human researcher but will need the assistance of computing methodologies. At the same time, as we will see, computers can only do their job, once an adequate phenomenology of human experience is fed into the process. 


\section{Pictorial semiotics as the flickering light at the end of the art historical tunnel}

Semiotics is a discipline whose aim is to lay bare the rules and regularities which govern the use of signs and other meanings in human beings as well as in other species; as well as to discover the emergence of these meanings in evolution, child development, and socio-cultural history. Pictorial semiotics, as a subdomain of general semiotics, has to account for the similarities and differences between pictures and other signs and meanings, structurally as well as diachronically, in the threefold sense indicated above. Semiotics, then, is neither a method nor a model, but it makes use of different models and methods. One well-known model used by semiotics is the structuralist one, according to which everything is organized into binary oppositions, a particular variant of which is the Greimasian Square; and another familiar one is the hierarchy of trichotomies characterising the Peircean approach.

\subsection{The scope of pictorial semiotics}

It is thus the business of semiotics to ascertain general facts about objects endowed with meaning, in our case, about pictures, a task which includes both determining how pictorial meanings differ from other signs and significations, and what kinds of meanings are contained inside the limits of variability set by the texture of the pictorial sign. Semiotics, then, is a nomothetic science, a science directed at the elucidation of rules and regularities attendant on each and every case of signification.

In the present case, this is to say our object of study is the system underlying all extant pictures, as well as those about to be produced. In linguistics, the system is often understood at the lists of elementary units available and the rules for their combination, but this conception is, for obvious reasons, much less promising in the case of pictures. Rather, pictures and pictorial kinds may have to be conceived as rules of transformation applied to the visual world (Sonesson 1989a: 251-300; 2011). The essential point here, in any case, is that generalities, rather than individual characteristics, are our subject matter. No doubt, we cannot expect these generalities to be as general as in the case of linguistics, at least not on this early stage of study, for each single picture clearly involves a formidable number of meshed mechanisms of transformation, thus depending on its belongingness to a construction type, a means/ends category, and a channel division, in addition to the properties stemming from its motives, and the manner in which it has been apprehended. But at least as a distant goal, we are directed at generalities. 
In the following, we will be particularly interested in the seminal work of Jean-Marie Floch, because nobody has gone further than he did in attempting to apply models and methods to the study of pictures, although, at the same time, paradoxically, he explicitly denies the pertinence of the quest for photographic specificity (Floch 1986a:11), and, more surreptitiously, also for the specificity of pictures generally.1 On one hand, he claims as his task to account for the particularities of a given photograph, and on the other hand, he declares semiotics should define other categories which cross-cut such as are socially accepted, like picture, art, and photography (Floch 1984:11; 1986a:12). Both these opposed alternatives to a study of photography and other socially accepted pictorial kinds are explicitly present in Floch's work, but it is not at all clear how they could be reconciled. And while the first interpretation seems to make nonsense of semiotics as a science, at least of its pretentions to be something else than good old art history, the second appears to opt for a positivistic approach of the most gratuitous kind.

But, of course, the fundamental issue here is to find out what Floch is really doing in his token analyses, but this is not quite easy, for in actual fact, each one of Floch's studies appear to be somewhat different. Thus, in his analysis of the advertisement for the cigarette brand News, Floch (1984) claims to be using the same approach as employed beforehand when studying Kandinsky's semi-abstract painting Composition $I V$, and although there are in fact important differences between these two analyses, which we have noted elsewhere (Sonesson 1989a:150; Section 1.3), the basic operations pertaining to expression and content of the iconic and the plastic layers are indeed identical. Nevertheless, the categories resulting from these operations are of such a general nature, that they could hardly be said to delimit any peculiar kind of discourse, which cuts across the divisions of abstract painting and photography. In both cases, as in many others, Floch discovers a plastic organization in terms of binary contrasts, notably between continuity and discontinuity, expressed in the form of a proportionality which evokes Lévi-Strauss' analyses of myths. This seems a pre-ordained conclusion. It is possible for these categories to be properties of all discourses, but then they are incapable of defining new categories of discourses, simply because they are too abstract.

\subsection{Four methods of semiotic study}

Although our study is ultimately concerned with generalities, it may possibly begin from

\footnotetext{
${ }^{1}$ The only other contribution coming close to being relevant for the present inquiry is that of the early Felix Thürleman (1982: 1990), but space won't allow us to engage with it in the present text. For a general overview of pictorial semiotics, see Sonesson $(2010 ; 2014)$.
} 
particulars. Indeed, we have distinguished elsewhere (Sonesson 1988; 1989b, using somewhat different terms) four different approaches to pictorial semiotics characterized by type analysis, token analysis, experiment, and token classification, which must be situated somewhere in between system analysis and text analysis.

Type analysis turns directly to the rules of the particular semiotic resources involved or, rather, the intuitions we have as users of this resource; and the most rigorous variant of this kind of analysis is what Husserl's calls imaginary variations, though in the case of social phenomena as those with which semiotics is mainly concerned, imagination may actually be less free, indeed bounded by the limits of structure (Sonesson 1989:15). The kind of reasoning employed by Umberto Eco (1976) to argue that iconical signs are arbitrary is of this kind, as are, in part, the arguments presented by Sonesson (1989a) to refute this idea. So is also the application of Peircean categories to pictures (Deledalle 1979; Jappy 2010), though imagination is here limited by the hierarchy of trichotomies. As we will see below, such an analysis may be computer-simulated, but since we are interested in understanding human picture perception, the properties which are varied have to be determined beforehand to be pertinent to human perception (Section 2.3$)^{2}$.

Token analysis, on the other hand, takes its point of departure in a meaningful token, that is to say, in a singular occurrence, such as a picture, and employs it to derive the rules of the system; but of course, in order to be in any sense reliable, such a method supposes the application of the procedure to a series of tokens, which, on account of other evidence (mostly from type analysis), may be supposed to have something in common, and in such a way that the results of the latter analyses are continuously projected back to the earlier ones to adjust the preliminary results. Put in other terms, such a procedure can only be valid if it is applied repeatedly to a series of instances, if the general principles are modified according as new instances yield to the analysis, and if the principles are reapplied to the instances earlier considered, in the light of the new insights resulting for the later analyses.

In his study of the Panzani publicity, Roland Barthes (1964) certainly claimed to go through the first part of this procedure; but he never tried out the analysis on other instances to verify the principles; and one may rightly doubt that, in the end, he had any model to apply in the first place (Floch 1978; Sonesson 1989a: 114-149). Later semioticians, such as Floch (1984; 1986a; 1990) and Thürleman $(1982 ; 1990)$ have come closer to applying the same model to

\footnotetext{
${ }^{2}$ Computer analysis may of course be applied to pictures with quite different purposes, which will require different properties to vary, but this does not make the latter properties any more physical than the former.
} 
several instances of the object studied, but in fact they seem to modify the model in relation to each instance, without taking into account the changes taking place. Thus, for instance, Floch postulates that all pictures must be divided into two main areas, and most of the time he makes the division opposing the right to the left part (though not necessarily in the middle). However, there is at least one instance, the analysis of the Nude by Eduard Bourbat, where Floch (1984) makes the binary division in terms of a piece in the middle and its background, without commenting on this very different perceptual configuration. Different kinds of pictures may indeed require different models, on some level, but these differences should then be systematically correlated with different kinds of picture signs.

Experiment, again, supposes the construction of artificial tokens, the belongingness to the resource of which is determined by the judgments of native users of the resource; or else the creation of partial tokens, which are to be completed in accordance with the rules of the system by the native users of the resource. There were some examples of this kind of study in early pictorial semiotics, notably as realised by René Lindekens (1976) and by Martin Krampen (1983) and collaborators, but on the whole, this method has been little used. A few psychologists, with little notions of semiotics, notably Judy Deloache (2004, etc.) and collaborators, have studied children's' notions of pictures. Recently, Sonesson and his collaborators have been involved in some experimental studies, which investigate pictorial understanding in children and apes (e.g. Lenninger 2012; Zlatev et al. 2013; Hribar et al, 2014; Sonesson and Lenninger 2015).

Token classification is similar to type analysis in its developed form in that it is based on an intersection of two or more conceptual series, the compatibilities of which are tried out in the analysis. But these compatibilities are not tested on a purely conceptual basis, but by spotting actual examples, answering to that particular constellation of features defining each single case. The result of a token classification is thus a series of analyses of tokens, but unlike what occurs in real token analysis, there is no attempt to account completely for the given picture, which is characterized only to the extent that it realizes that particular constellation of features (Sonesson 1989b). Thus, in a drawing showing Captain Haddock with a bottle instead of a pupil is his eyes, Groupe $\mu$ (1992), which introduced this method, would say that there is a presence of a bottle in an unexpected place, and this bottle appears as an integral part of (conjoined with) a body where a different part would be expected. The race then is opened to find illustrations for the three other combinations of the dimensions presence/absence and conjoined/disjoined. 


\subsection{The principle of binary division}

As we noted above (Section 1.2), Floch always begins his analysis by dividing a picture into two parts on the plastic level, each of which may then again be divided into two parts. This division in purely intuitive, as Floch admits. But then he starts looking for different plastic dimensions, whose opposite terms are realized in each of the binarily divided fields. One of the pictures analysed in this way by Floch (1984:48) is the photograph Les Arènes de Valence, photographed in 1933 by Henri Cartier-Bresson. In his analysis, Floch proceeds exactly as suggested above, proposing a division of the picture into a smaller part characterized by dark, blurry shapes and a bigger part containing light, distinct shapes.

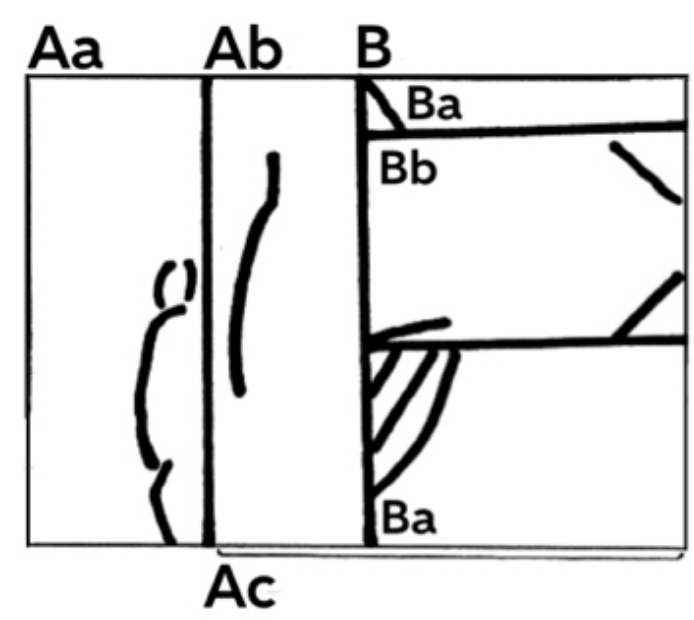

Figure 1. Les Arènes de Valence analysed by Sonesson (A vs B). Photo available at: http://pro.magnumphotos.com/Asset/-2S5RYDI0Q9GT.html

Nevertheless, this picture can also be divided binarily in at least two other ways, either, closer to the way Floch makes the division, into two more or less equivalent fields, or, more similar to the way Floch makes the division in other cases, such as the Nude by Eduard Bourbat, into prototypical shapes, that is, into a quasi-circle opposed to a quasi-rectangle (See Figure 1 and Sonesson 1989b:90). Although these divisions are just as intuitive as the division made by Floch, at least the second one can be supported by much more different dimensions, the opposite terms of which are manifested in the two fields, than Floch's original division. Thus, it seems that there are other intuitive divisions of the picture which may be at least as fully supported by the position of binary oppositions as the one proposed by Floch. A more fundamental question, however, is whether all pictures can be adequately divided by binary contrasts, in one way or another (Sonesson 1989a:132). 


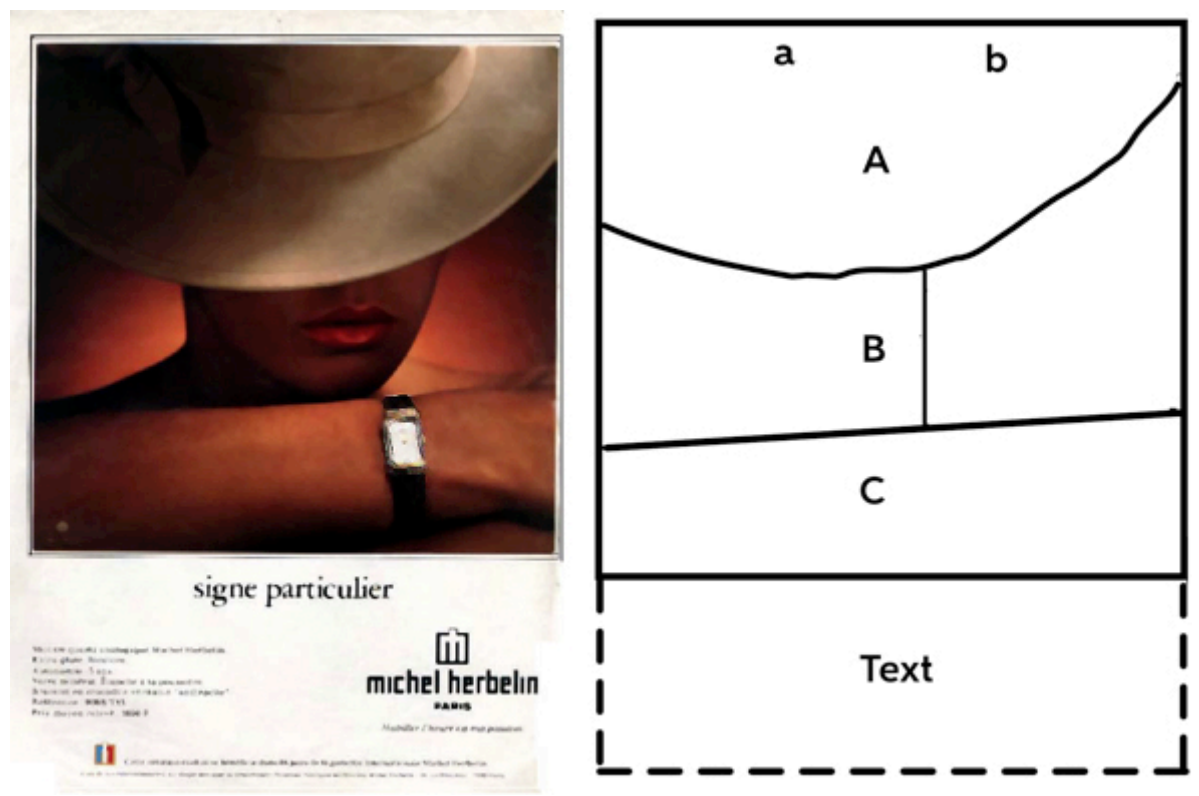

Figure 2. The girl-with-a-hat-and-a-watch as analysed in Sonesson (1988).

A more open-ended analytical procedure would be to take into account all imaginable divisions of a picture, whether they are binary, trinary or whatever, and to investigate which of these divisions can best be supported by a great quantity of plastic dimensions. Sonesson (1988: 114) carried out a plastic analysis of this type as applied to a publicity picture which he called the girl-with-a-hat-and-a-watch (Figure 2). We here adopted an analysis, similar to that employed by Floch (1984), but which started out from a trinary division of the picture, which, in this case, seem more intuitively justified, and then tried out all different possible combinations. The method contained four separate steps:

1) The picture was segmented into three horizontal bands, the middle one of which was also segmented further into two vertically demarcated portions, all of which could be correlated two-by-two, with the aid of attributes which dominate the attribute hierarchies of the respective areas.

2) Inside each correlation, we opposed one of the areas to the two others, in order to derive such contrastive pairs as characterize them; but on the background of these differences we also attended to similarities, as long as they could be read as continuities from one area to the other. We then also noted contrasts obtaining between two areas singly, and the deviations between the two sub-sub-areas of the middle band.

3) We ascribed properties derived from the different oppositions to the areas, inside which fall the poles of the oppositions; and we derived meanings for each one of the fields, relying on findings from psychological research and to some extent on personal intuitions. 
4) Finally, we attended to the meanings generated by the textual block, also considered as a visual element; and we confronted the meanings derived iconically and plastically for the different areas.

We used $\mathrm{A}, \mathrm{B}$, and $\mathrm{C}$, to refer to the different horizontal bands, and $\mathrm{Ba}$ and $\mathrm{Bb}$ to indicate the two sub-fields of field B. There is a colour correlation (beige vs yellowish brown) which opposes field $\mathrm{A}$ to $\mathrm{B}+\mathrm{C}$; and a shape correlation (rounded vs angular shapes), which accounts for the primary opposition between fields $\mathrm{A}+\mathrm{B}$, on the one hand, and field $\mathrm{C}$, on the other; and a correlation of homogeneity differentiating field B from fields $\mathrm{A}+\mathrm{C}$. Features which are considered to serve as demarcative traits of the different fields are taken to dominate the respective feature hierarchies; also marked are such features as are continuities (isotopies) from one field to another, again in opposition to the third field. For the full analysis, see Sonesson (1988: 114-146).

Now doubt this is too big a task for a human researcher once it is applied to a series of pictures, as token analysis requires. If we want to implement the tall task thus set up, we need to develop computer algorithms for the analysis of the plastic layer. Algorithms for recognizing faces are now part and parcel of ordinary computer interfaces. This is not surprising, since identifying faces is the first thing infants learn to do. But it involves what Floch called iconic language (our pictorial layer). The plastic layer may, however, be more fundamental to our experience of pictures, as different from ordinary perception. As has been shown by Sonesson $(1988 ; 2014)$, many of the properties taken into account by Floch, Thürleman, and others, correspond to attributes isolated by psychologists, such as Sander \& Volkelt, Werner \& Kaplan, Arnheim, etc. Before we enter the discussion of computer methods in the second part of this paper, something has to be said about the distinction between the plastic and the pictorial layers of the picture.

\subsection{The specificity of the plastic layer}

An important result of pictorial semiotics, which seems to have been discovered independently by the Greimas school and by Groupe $\mu$, is the division of the standard pictorial signs into two layers: the iconic function, which is thought to be the feature by means of which the picture depicts one thing or another, normally corresponding to a fragment of a scene as perceived in real experience; and the plastic function, which is the meaning conveyed by the picture as a surface on which colour spots are disposed in a particular way, i.e. the picture considered as it if had been a piece of abstract art. As Floch 
points out, studying the plastic function of any picture amounts to treating figurative pictures as abstract art. Something that is, on one level, a sun or a flower, and even a human body huddled together, may on another level appear as a circle or another roundish shape.

It seems that for the Greimas school, as well as for Groupe $\mu$, iconicity is that aspect of the picture that creates the illusion of seeing a scene from the real world, as given in direct perception, while the plastic layer, whose expression is constituted by the flat surface of the picture, generally is taken to embody more abstract meanings. However, this is no more the iconicity in Peirce's sense, which serves to define a relationship between an expression and a content, and that can be applied to both the pictorial function, which creates the illusion of seeing the reality of perception, and to the plastic function, whose contents are generic concepts, having the actual properties, not the illusory properties, of the flat surface as expression. While what is here called the iconic function connects relatively concrete expressions and contents corresponding to familiar objects within the individually perceptible world of our experience, plastic language, such as we just characterized it uses shapes whose properties are abstract, to convey to us meanings usually at even higher levels of abstraction (roundness for nature, etc.). In this sense, the latter may well be iconic, to the extent that they are synesthetic and/or physiognomic, which is part of the secret of abstract art. To avoid confusion, however, it is important not to use the same term for two notions which do not have to coincide: we will call the rendering of perceptual appearances the pictorial function and oppose it to the plastic function which has to do with the meanings of shapes and colours. The pictorial function is always iconic, but there are also other types of iconicity, some of which are characteristic of the plastic layer.

A further question is how we are supposed to be able to discover the meanings of the plastic layer. Floch (1981b) sets out to do this in his analysis of Kandinsky's Composition IV. According to Greimas and Courtés (1979), the criteria which are to be used in the segmentation of texts comprise the exchange of acting persons, transitions in time and place and changes of emotional atmosphere. Unfortunately, these criteria only seem applicable to verbal texts, or perhaps to texts extended in both space and time, and Floch rightly ignores them. That seems to leave him with intuition alone, but he does have a kind of regulative principle, as we saw above (Section 1.3.), the idea that all relevant properties must form binary contrasts, and that many of those will join to form bundles of similarities.

Even the principle of binary contrasts will not tell us how to find the first element of the pair, as we have pointed out (Sonesson 1989a:152): once we have A, we can find non-A, but that 
leaves us with the problem of finding A. This first phase must therefore remain intuitive. In order to gain semiotic status, as Floch says, the elements must be repeatable, like the units of linguistics, i.e. they must be susceptible of returning in identical form in many texts. That brings us to the second phase of the analysis: we must define a corpus, i.e. a collection of texts, which we suppose to derive from the same semiotic system, and in the analysis of which we will verify the identity and extension of the units proposed in the first analysis. In linguistics, the result of this procedure could very well be that what appeared to be one unit must now be dissolved in two or more, or that the limits between the units must be placed elsewhere. In Floch's case, no such revisions take place. The corpus used is the collection of Kandinsky's works which are more or less contemporary with Composition $I V$. But this corpus is not really used to corroborate the units of expression of the plastic level already postulated; as we shall see, it is employed to discover their meaning.

Floch intends to find the meanings expressed in Composition IV scrutinizing other works of Kandinsky made more or less at the same time, where he deems the plastic layer to more or less similar to that of Composition IV, and which happens to be figurative paintings, that is, they come closer to represent objects of the real world, and they have titles saying something about their content. Sometimes, Floch goes beyond this principle to pay attention also to the particular context: the light area in the middle field of Composition IV should only be compared to other light fields also found below dark, bluish masses (1981b:145). Thus, while Floch is supposedly searching for the content plane of the plastic layer, he is actually all the time concerned with the content plane of, in his terms, the iconic language (our pictorial layer), because he presupposes, instead of demonstrating, that they must be identical. Sometimes, it is true, he also notes the emotional atmosphere common to particular contents, or rather, to the manner in which they are expressed, but also these seem to be derived from the contents.

But why should we bother to analyse the plastic language if what it tells us is anyhow the same thing that the iconic language tells us, and in fuller detail? While Floch is perhaps not aware of this problem, there seems to be at least one interpretation which makes this procedure worthwhile: perhaps different artists will correlate the plastic and the pictorial layers in different ways, so that the correlation itself becomes significant. For instance, using the same plastic shape for a captive princess, a person in a fight, a woman holding her chin, etc., Kandinsky tells us they have something in common, i.e. he creates a new category that no other artist would have used. Thus, he is segmenting the Lifeworld in a new way. Of 
course, on this interpretation, he does not tell us what he thinks they have in common. Thus, even if there is redundancy between plastic and iconic language in the case of each particular artist's work, the double analysis would not be vain.

Now, if we can attribute specific meanings to the figures on the plastic layer, the correlation between the plastic layer and the pictorial layer may tell us something worth considering about some pictures as opposed to others, for instance, about Kandinsky's pictures, which would not be true of all other pictures. Elsewhere, we have tried to show that something like that holds true of the work of Rothko, relying on plastic meanings which are fairly wellestablished, such as those of roundness and angularity (Sonesson 1994; 2014). However, most plastic meanings are so far unknown, and have to be established by experiments, in the tradition of what has already been done by Gestalt psychologists, as well as by Lindekens and Krampen (Section 1.2). Prior to that, however, it will be useful to know what kinds of plastic expressions exist, or at least which are the most common.

\section{Computing sparkles: digital methods for pictorial semiotics}

In the first part of this paper, we studied the contributions of structural semiotics to modelling the meaning conveyed by pictures, and we have shown that, unlike traditional art history, and certainly unlike poststructural and postmodernist visual studies, these analyses have taught us a lot about the organization of pictorial meanings. At the same time, we have suggested that, given the way in which these analyses were performed, the gap remained huge between the ambitions implied by the models, and what they accomplished, in particular with respect to the possibility of generalizing the results. One of the barriers to fulfilling this goal involves manually implementing a model on numerous instances of pictures. In this respect, computing methods might come to rescue once an algorithmic procedure has been described into which the results of a thorough phenomenological analyses have been fed. We do not pretend, in the following, to show that computers are presently up to the task of resolving all the queries formulated in the first part of the paper. This section acts more like a proof of concept: some ideas for how we could go on from here.

\subsection{Plastic expressions in digital images}

In their seminal study on plastic signs, the classification proposed by Groupe $\mu$ (1992) distinguished three main categories -coloremes, texturemes, and formemes-, each one of them containing more basic units (Table 1). 
Table 1. Plastic categories according to Groupe $\mu$

\begin{tabular}{|l|l|}
\hline Category & Units \\
\hline Formemes & Direction, Dimension, Position \\
\hline Texturemes & Textural unit, Textural rule of repetition \\
\hline Chromemes & Hue, Saturation, Brightness \\
\hline
\end{tabular}

It will be necessary for our purposes to verify if the basic units can be described formally in terms of computing operations and translated into algorithmic procedures. We turn our attention now towards the field of visual computing, where images ${ }^{3}$ are studied from different perspectives. For example, image processing is concerned with processes that are carried out once the image has been digitized and stored in a digital format. It comprises techniques such as image representation and description, image formation (quantization, sampling), image analysis (segmentation, feature extraction), image restoration, colour processing, image transformations (pixel processing, geometric transformations), and image compression. As for computer vision, it concentrates on gathering, describing, and analysing information as it is presented in perception. It also uses image analysis but strives to go from a syntactical description of objects and scenes to a semantic level, simulating the ability of human beings to organize perceptual experience (by means of clustering, learning, and recognizing shapes). Finally, computer graphics (CGI) deals with producing and synthetizing information. In relation to computer vision, it adopts an inverse procedure: it constructs and produces images based on a given computational model, most commonly based on polygons, surfaces, and volumes.

In contemporary everyday practices, the first aspect to take into account about the investigation of plastic expressions in the digital realm is that images exist only as simulations on screen (i.e. as versions, renderings, or interpretations). The complexity of material processes underlying the visualization of an image means that almost any instance is de facto an original, depending on variables such as the types of processor, application software, operating system, screen devices apart from numerous parameters that can be customized (Groys 2016). Second, if the image depicted on the screen is a momentary lapse of vision, the

${ }^{3}$ The term image will be used hereafter mainly to in relation to its technical specificity. When applying methods of digital images to pictorial semiotics, it is useful to distinguish images from pictures in the sense of everyday language. 
expression plane of an image has to be found at the deeper layer of file formats, which are the components that are stored and transmitted in computing devices. On the one hand, there are raster formats based on discrete units called pixels that will be mapped directly onto the amount of screen pixels available by the display device. Examples of such formats are JPG and PNG images. On the other hand, vector-graphics rely on geometrical properties of images, which are described either with ASCII characters or with binary digits. Examples are SVG and other XML-based formats. Given that human beings and computers have quite different evolutionary histories, and thus different etics (equivalent to the phonetic level in language), the basic problem facing us is how to arrive at a similar kind of emics (equivalent to phonemic level in language), notably as far as plastic categories such as colours and forms are concerned.

These two fundamental aspects of visual information, as given to the human eye and as it is normally fed into the computer, must be kept in mind when we proceed to create formal descriptions that will inform methods for the analysis of images.

\subsection{Formal descriptions of the plastic layer}

In terms of visual computing, an image is commonly analysed by quantifying its visual content. This method implies that input images are mainly in bitmap format, which consists of finite numerical values, called pixels, organized into a two-dimensional matrix. Thus, when an image is rendered on screen, a series of algorithms parse the values in the matrix to detect, extract, and organize visual and spatial data. At the lowest level, image-processing techniques are based on descriptions called features that will provide measurements of an image, or alternatively small regions of it. The type of existing content descriptors matches exactly the classification mentioned by Group $\mu$. In specialized literature, we find colour descriptors, shape descriptors, and texture descriptors.

Colour descriptors employ quantization techniques that help to map, reduce, or index the amount of colours available in a bitmap image to a different scale. These techniques can be appreciated in image acquisition (for example, when a scene of the natural world is captured through the camera lens, the colours have to be sampled for digital representation) or in image content-based search (for example, when a corpus of information can be searched or sorted by colour; Parker 2011:399). But essentially, the way in which chromatic values are stored and managed is based on a colour model, for example, HSB (that defines colour as a combination of hue, saturation, and brightness features) or the canonical RGB (or 24-bit, where images 
have three layers of 8-bit pixels each, resulting in 256 different values for each component, in this case, red, green, and blue).

Current methods for description shape and texture descriptors are also based on pixel values. These techniques commonly derive from feature detection and object recognition tasks. The algorithms designed for such routines analyse a digital space according to the entire image plane (the total area or surface) or local elements such as corners, edges, regions of interest (ROI), edges, lines, curves, or surfaces.

At this point, it is possible to formalize relationships between the basic descriptors. These are known as geometrical features and some of the most prominent algorithms have emerged from combinations of size measurements. Table 2 shows metrics determinations for shape descriptors adapted from (Russ 2011: 600).

Table 2. Shape descriptors

\begin{tabular}{|l|l|}
\hline Shape descriptor & Formulae \\
\hline Form factor (circularity) & $4 \pi *$ Area / Perimeter \\
\hline Roundness & $4 *$ Area $/ \pi \cdot$ Max Axis $^{2}$ \\
\hline Aspect Ratio & Max Axis / Minor Axis \\
\hline Elongation & $\begin{array}{l}1-\text { Long Side Minimum Bounding Rectangle / Short Side } \\
\text { Minimum Bounding Rectangle }\end{array}$ \\
\hline Convexity & Convex Hull Perimeter / Perimeter \\
\hline Compactness & $\sqrt{4 / \pi} \cdot$ Area / Major Axis \\
\hline
\end{tabular}

The notions of perimeter and area refer to the outer contour of an object (also called particle or blub) and they can be associated to the dimension category observed by the Group $\mu$. In respect to the other two eidetic categories, direction and position, we can determine spatial relationships (Del Bimbo 1999:27). On the one hand, once an orientation is established, the direction can be described as from left to right or from top to bottom. The metrics of directional relationships are typically the distance or angles between entities. On the other hand, topological relationships are described in terms of disjunction, adjacency, containment, overlapping. Usually they are formalized in natural language, but we can also use set 
operations as logical propositions.

Of course, these are not the only shape descriptors. Other models of measure can be designed with different methodologies. For example, fractal analysis summarizes the roughness of edges; spectral analysis corresponds to Fourier descriptors that define shapes mathematically; and topological analysis use descriptors that quantify the number of regions or holes between edges in an image (Gonzalez 2008).

We can use as many categories as necessary in a given project or we might even envision innovative relationships and create new algorithms. In the end, however, the final outcome of an image analysis gives a series of quantifiable values organized as a data table and, more interestingly, the same procedure can be applied to a collection of multiple images notably through batch processing. The following step, as it is practiced today in computing fields such as machine learning, would be to correlate high-level human-nameable semantics. We talk about classifiers: holistic descriptors (e.g. furry, shiny, etc.) and localized parts (e.g. has-legs, has-wheel (Chen 2017:50)) that assembled together can generate even broader classifiers, like human, animal, or vehicle.

In the following section we discuss a practical case in which we put in action the visual descriptors mentioned on a corpus of painting images by Mark Rothko.

\subsection{An experimental implementation of pictorial digital methods}

We constituted a corpus of analysis based on paintings by Rothko, inspired by a previous work by Sonesson (1994) in which he applies segmentation principles based on prototypical shapes and identifies correlations of plastic signs. For practical reasons, our corpus was created from the public archive wikiart.org ${ }^{4}$. We obtained 201 compressed digital images, in JPG format, with the resolution of 72 dpi and in varied sizes (from 500 to 2000 pixels width).

The environment in which we implemented image-processing routines was Image ${ }^{5}$. Our first task was to extract and organize colours for each image of our corpus. We relied on HSB and RGB colour models to describe our results. Two different scripts for colour extraction returned single values that summarize and weight the most frequent chromatic expressions in an image. Thus, we can obtain the mean, the median or the standard deviation (StDev) of hue, saturation, and brightness. In a similar manner for RGB, we obtain the same statistical metrics

\footnotetext{
${ }^{4}$ Obviously, a more robust study of the artist's work would involve scanning and digitizing the original pictures with our own methods and parameters.

${ }^{5}$ Image $\mathrm{J}$ is a scientific application distributed as open-source cross-platform software by the National Institute of Health, developed since 1987 by W. Rasband. https://imagej.nih.gov/
} 
for each colour channel (red, green, blue). Table 3 shows a fragment of our data table.

Table 3. Fragment of colour quantization data

\begin{tabular}{|l|l|l|l|l|l|l|}
\hline Image Id & $\begin{array}{l}\text { Hue } \\
\text { StDev }\end{array}$ & $\begin{array}{l}\text { Saturation } \\
\text { StDev }\end{array}$ & $\begin{array}{l}\text { Brightness } \\
\text { StDev }\end{array}$ & $\begin{array}{l}\text { Red } \\
\text { StDev }\end{array}$ & $\begin{array}{l}\text { Green } \\
\text { StDev }\end{array}$ & $\begin{array}{l}\text { Blue } \\
\text { StDev }\end{array}$ \\
\hline 186 & 15.2845 & 66.9679 & 60.6343 & 60.8013 & 58.9752 & 65.5233 \\
\hline 199 & 41.5579 & 31.813 & 35.3704 & 34.799 & 33.5895 & 29.7562 \\
\hline 36 & 27.7704 & 36.712 & 49.5433 & 49.5508 & 39.3557 & 20.6593 \\
\hline 100 & 69.4059 & 45.5303 & 42.2035 & 50.5932 & 31.7156 & 20.2424 \\
\hline 108 & 71.0471 & 45.9049 & 36.1251 & 36.7194 & 24.3674 & 17.3614 \\
\hline
\end{tabular}

At this point, the analysis of the multiple instances of our corpus requires the passage to second-order organizations to observe variations and correlations of data. Typical examples could be charts, plots, and graphs. For our purpose, we generated a scatterplot matrix (SPLOM) where each mosaic shows a different correlation between chromatic values, for example hue vs. saturation, hue vs. brightness, hue vs. red, hue vs. green, hue vs. blue, etc. (Figure 3). The usefulness of this representation is to contemplate the totality of combinations in order to start identifying patterns and clusters where we can focus in more detail. 


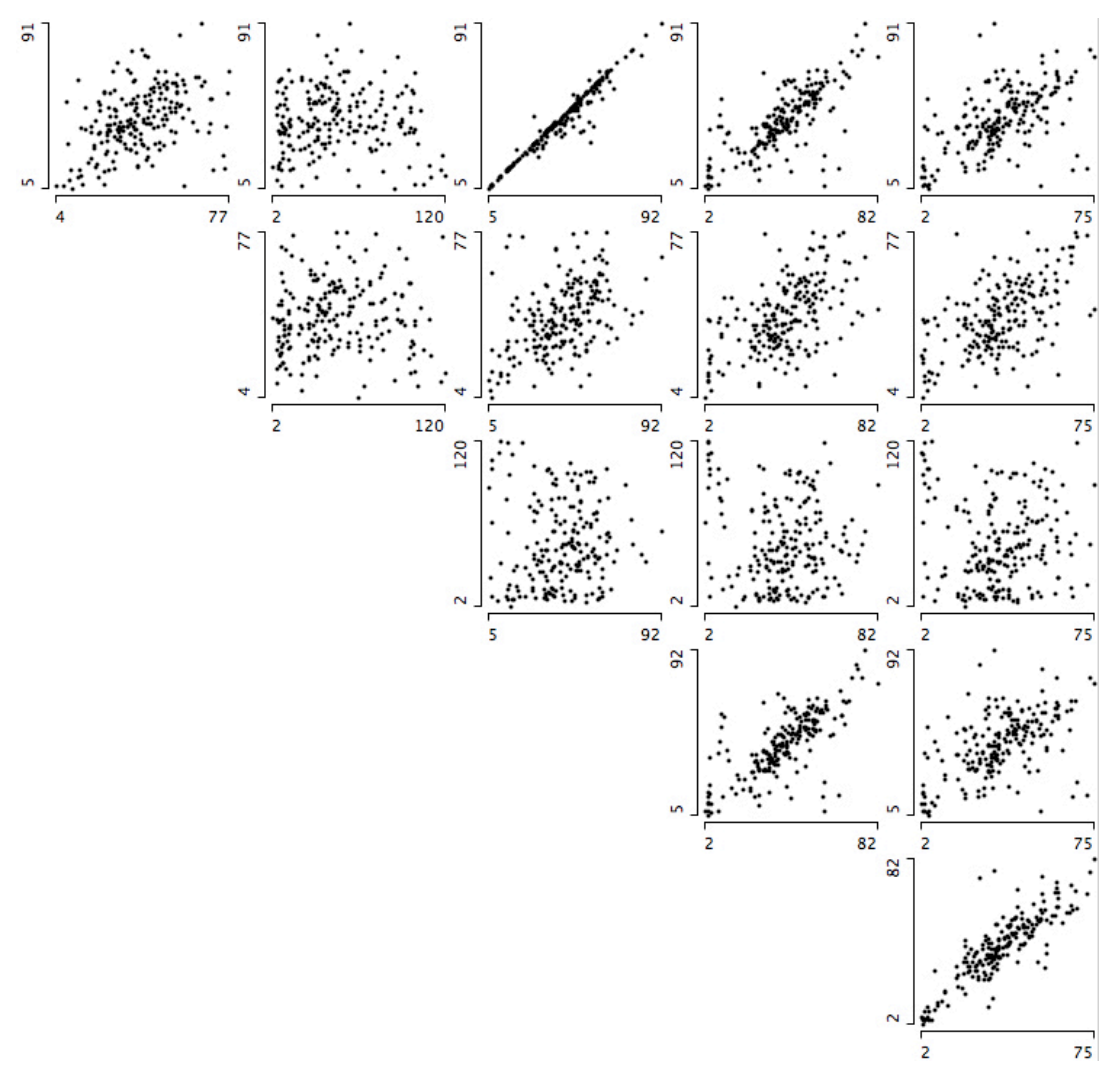

Figure 3. Scatterplot matrix (SPLOM) of HSB and RGB standard deviation values

Another graphical representation of the same data takes into account the theoretical form of colour models. For example, the RGB model specifies a cube, whose vertices map the relationships between red, green, and blue (and forming magenta, cyan, yellow, black, and white). The other model, HSB/HSV, is plotted with a cylindrical form where the top part corresponds to the 360 degrees of the hue values, the height to the brightness/value, and the distance from the centroid to the saturation.
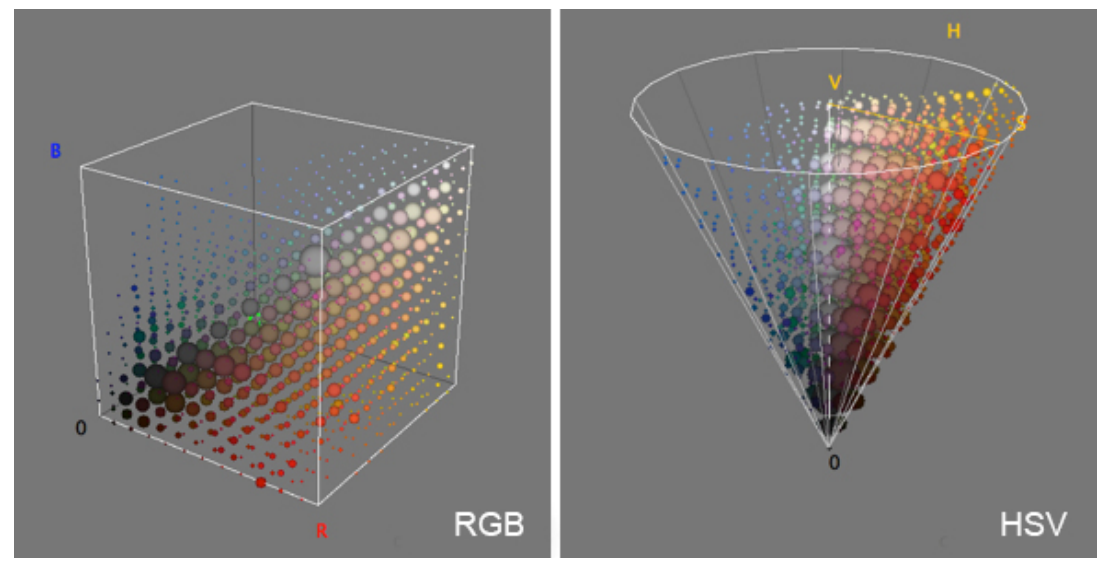

Figure 4. Colour quantization of our corpus of images 
Through these figures it is possible to gain insight about the colour signature specific to Rothko. Accordingly, it would be feasible to create similar representations to make comparisons of colour palettes for other artists, for entire periods, and even for types of pictures. For now, however, it is out of the scope to orientate our efforts in that direction and we will rather explore shape measures of our corpus.

Following the procedure for segmenting and correlating plastic dimensions that we listed in Section 1.3, we adapted a general routine based on the shape descriptors defined by Russ (Section 2.2) and implemented as an ImageJ script by G. Chinga ${ }^{6}$. The method implies first to transform true-colour images to 8-bit format; it then expects to delimit a chromatic threshold of the image that will highlight the most important regions to be measured. Predefined functions such as edge detection can be invoked to satisfy these requirements, or we can also parameterize our own settings. Furthermore, it is possible to obtain all the specific data in each region or to calculate the mean of the whole values into one single footprint. To exemplify with an image previously analysed by Sonesson (1994), Table 4 shows a fragment of data for the biggest regions in Figure 5.

Table 4. Shape measure of Figure 5

\begin{tabular}{|l|l|l|l|l|l|l|l|l|l|}
\hline Area & Perim & Width & Height & Angle & Circ. & Skew & $\begin{array}{l}\text { Aspect } \\
\text { Ratio }\end{array}$ & Round & Solidity \\
\hline 1153 & 810.10 & 324 & 22 & 0.13 & 0.02 & 0.86 & 26.58 & 0.04 & 0.23 \\
\hline 705 & 440.43 & 179 & 25 & 174.65 & 0.05 & 1.27 & 22.11 & 0.05 & 0.31 \\
\hline 660 & 513.71 & 108 & 34 & 173.79 & 0.03 & 1.01 & 6.10 & 0.16 & 0.29 \\
\hline 443 & 244.25 & 61 & 19 & 176.59 & 0.09 & 0.76 & 4.21 & 0.24 & 0.52 \\
\hline 431 & 285.97 & 118 & 12 & 1.20 & 0.07 & 0.94 & 12.55 & 0.08 & 0.40 \\
\hline
\end{tabular}

\footnotetext{
${ }^{6}$ Available online: https://imagej.nih.gov/ij/plugins/descriptors.html
} 


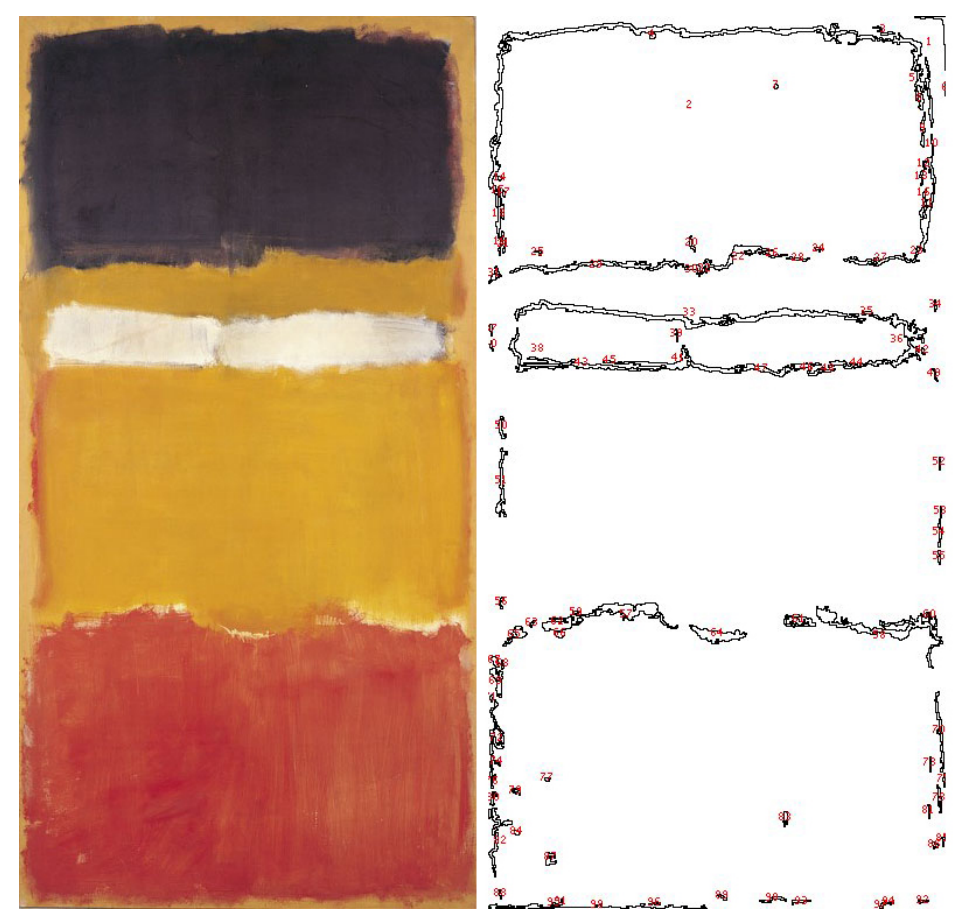

Figure 5. Regions and measures from Untitled, 1951

Such measures can be seen in relation to the prototypical shapes observed by Sonesson. The implicit circularity of shapes, for example, is given by a value between 0.0 and 1.0 where the highest tends to a circle and the lowest to a rectangle. While the results are approximate and may vary depending on the selected parameters, they are useful in combination with colour data to generate visualizations of similarity between pictures.

In sum, our data table was now completed with chromatic values and shape measures, besides categorical metadata such as title of the work and year of creation. In its current state, the table has 30 low-level descriptors per image that we exploit in two manners. First, in form of a plot of images that will help us identify similarities and patterns among the images. Second, from those observations we can test if the analysed correlations can inform an approach to image generation for experimental purposes.

For our first experiment, the plot of images, we employed the PCA (Principal Component Analysis) method in order to deal with our 30 low-level variables. PCA is widely used for reduction dimension of multivariate data sets of more than 10 columns. Overall, the technique consists in transforming the original data and producing new columns (also named principal components) based on the maximum variances of data. Moreover, the results are ordered by significance, which is of particular interest to map the most significant trends in the visualization process (Müller 2006). 


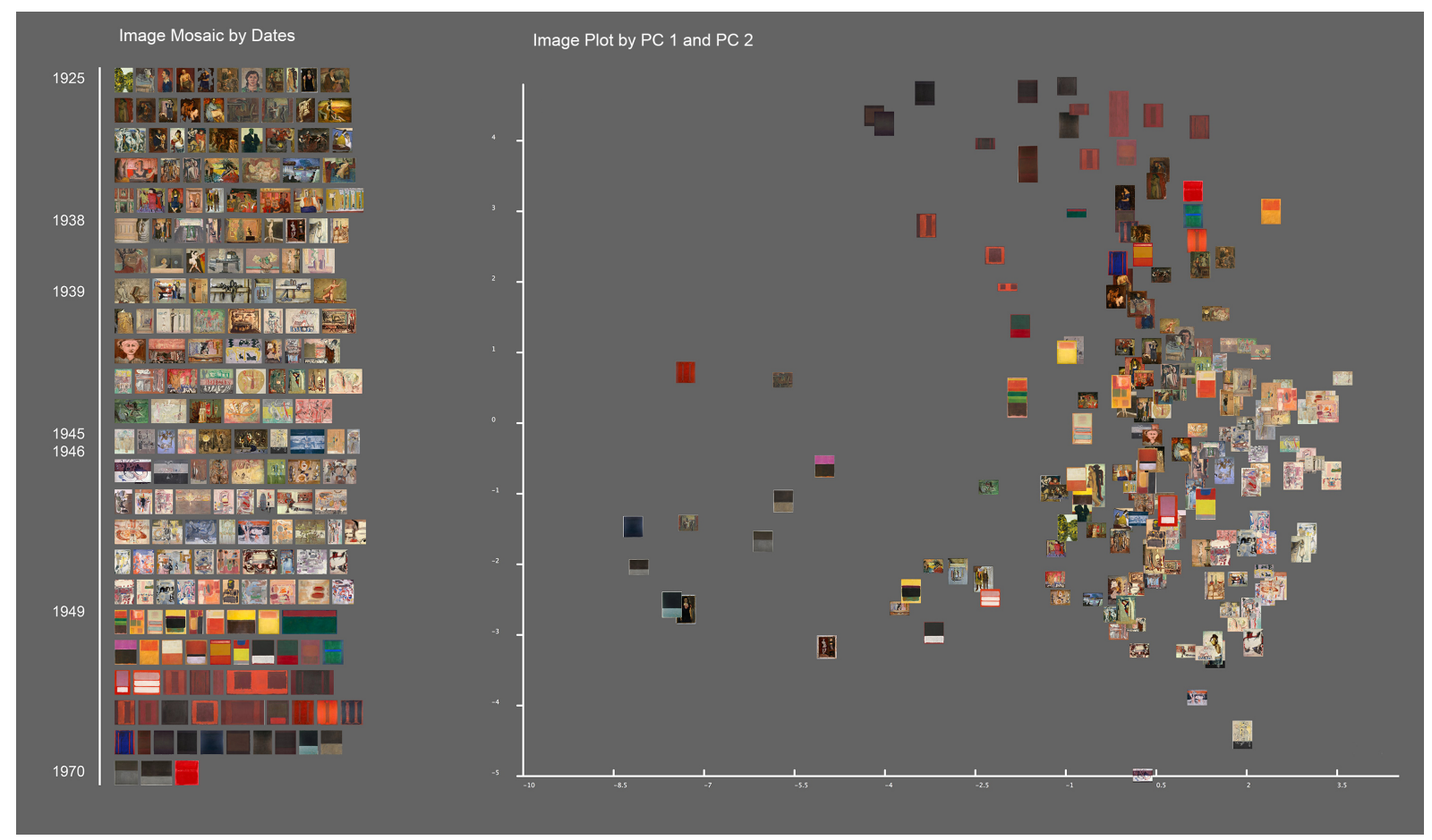

Figure 6. Image mosaic and image plot representation

In Figure 6 we can see two representations. To the left, we organized the 201 images as a chronological mosaic. We only highlighted with text annotations those year spans were variations in style are clearly visible. To the right, we plot the same images according to the first two principal components (PC1 and PC2). The technique of depicting actual images instead of simple dots is called direct visualization or media visualization (Manovich 2011) ${ }^{7}$. This figure serves as an analytical map for visual enquiries where different sorts of similarity emerge. For example, images appear grouped into spatial clusters that share colours, shapes, or a combination of both. Although some images are superimposed and may be difficult to spot as individual instances, the plot offers a record of overall trends and patterns. Consider the bottom-right part of the plot, which shows brighter colours with complex shapes in contrast to the top-centre and the left part, which corresponds to darker tones with simple shapes. In the case of Rothko, we can relate these tendencies to periods of a determinate style. Works mainly from his earlier figurative time (roughly from 1925 to the mid 40s), include a more diversified colour palette, while his later period (from late 40s until 1970) embraces more accentuated contrasts with more basic forms.

For our second data exploration, concerning image analysis and synthesis, we concentrated on

\footnotetext{
${ }^{7}$ We used the ImagePlot script for ImageJ, created by the Cultural Analytics Lab. Available online: http://lab.softwarestudies.com/p/imageplot.html
} 
the last 37 images of our collection, pertaining to the Rothko's later carer, from 1955 to 1970. In this sub-corpus, the relation between prototypical rectangles presents at least six variations: single, double, triple, quadruple, quintuple, and pair of vertical zones. Interestingly, each variation can be associated to a range of time and to a distinctive palette with traits like: dark saturated, bright unsaturated, analogous tonalities in combination with high contrast, and colours delimited to a determinate shape. Table 5 depicts, in chronological order, contour detection and the most frequent colours per image.

Table 5. Correlations between shape organizations and colours

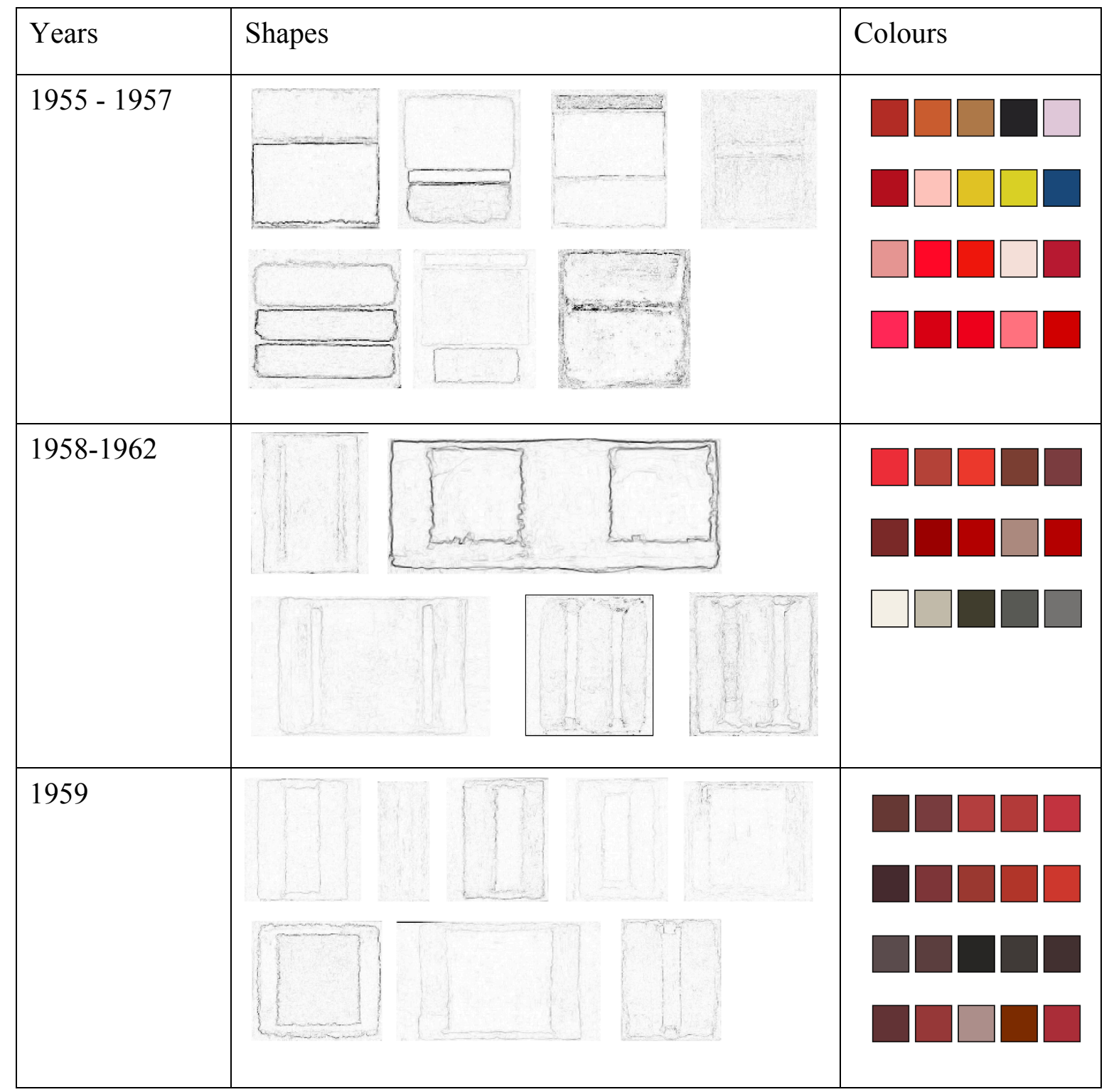




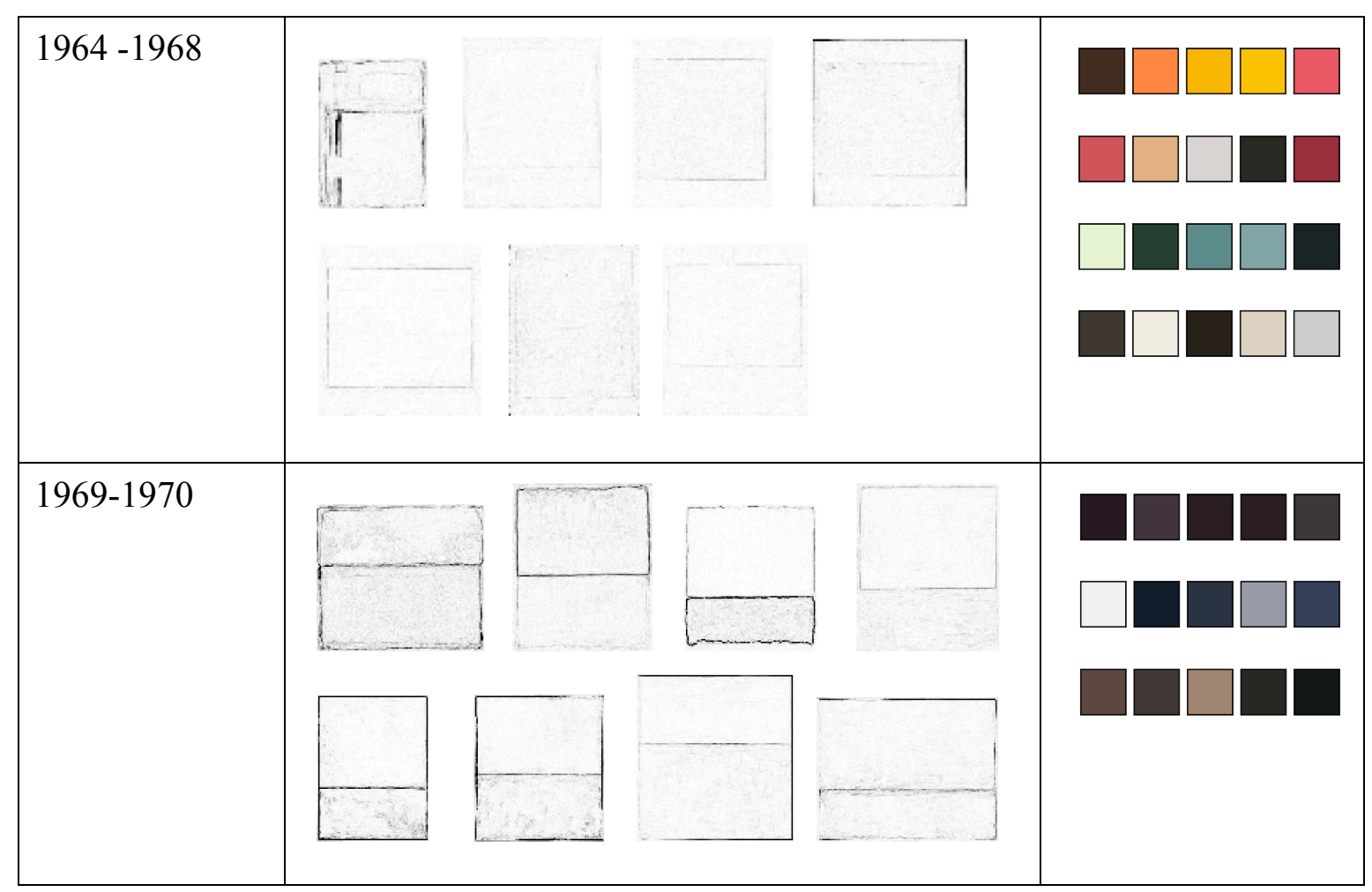

We relied on Table 5 as a visual guide to formalize correlations in computer code. Inspired by the work of Kirsch \& Kirsch (1988), we put our descriptions to test by means of image synthesis. With the intention to prepare supporting materials for empirical verification and to gather experimental data, we created image generators that furnish novel and potentially infinite instances of Rothko styles each time the user clicks on a button. Figure 7 shows several images dynamically generated. For this implementation, we opted to use Web languages, making it available as a public $\mathrm{URL}^{8}$. Indeed, as a graphical language, CSS currently allows us to formulate many of our correlations (shape and colour descriptors) in terms of style sheet rules that can be manipulated in real time with JavaScript. If synthetic images manage to mislead a viewer, when confronted with our interface, into believing she is seeing a new Rothko-like image, that means the rules defined by our generator prove to be effective. If so, the images generated are instances of configurations that may be characteristic, in this case, of Rotho's style, which may be usefully validated by other methods. At present, the experimental tests remain an on-going project that needs to be defined in collaboration with colleagues in psychology and cognitive semiotics.

\footnotetext{
${ }^{8}$ This an other representations are available online: http://ereyes.net/rothkoviz/
} 

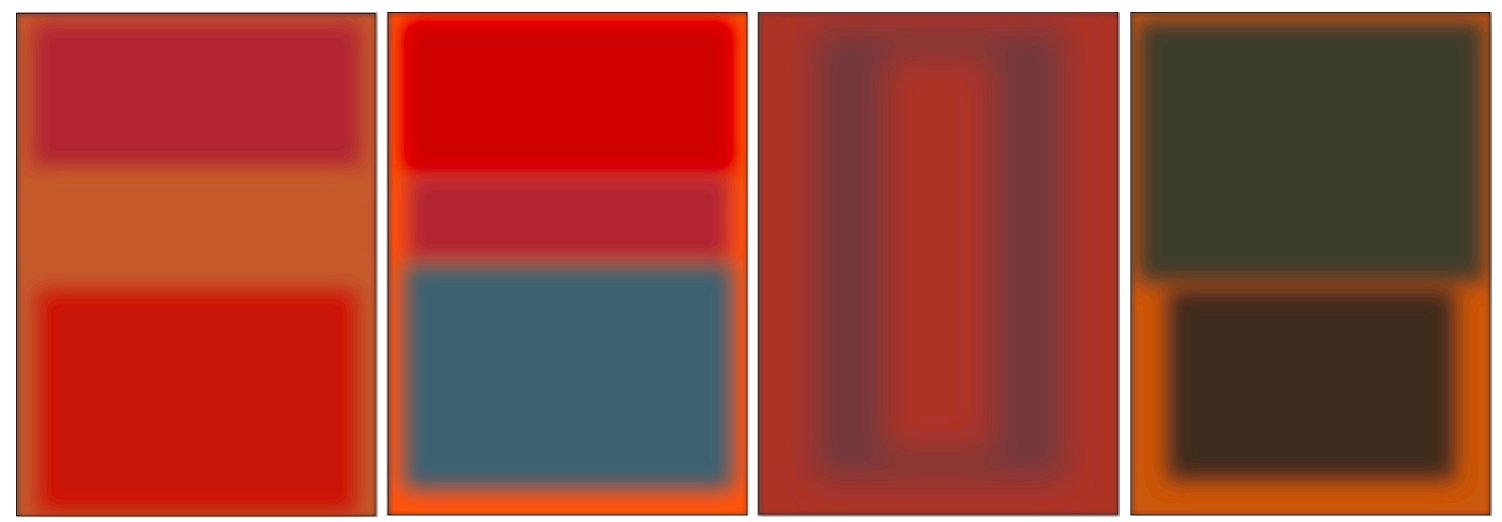

Figure 7. Rothko-style dynamically generated images

\section{Conclusion}

In this paper, we have rehearsed some of the critiques which may be addressed to the methods used so far in pictorial semiotics, explaining, in our first part why, in spite of being an immense advancement in relation to art historical analysis, these methods remain problematic. The main issue of structuralism, as well as current pictorial semiotics is the lack of application of one model to numerous instances of pictures. We pondered, in the second part of the paper, whether some help can be gained from computer technologies. The application of computer algorithms to images is already very advanced, but the adaptation of these technologies to the tasks set by pictorial semiotics is only at its beginnings. Therefore, we offered a preliminary approach to such an adaptation. As observed, this endeavour can at present only be considered a proof of concept. Indeed, the main obstacle before developing a full computer-aided analysis of pictures may not be technological, but rather phenomenological. We need to understand the nature of those holistic, topological, and physiognomic properties of perception on which human beings focus in order to make sense of pictures from a plastic point of view.

\section{References}

Barthes, R. 1964. Rhétorique de l'image. Communications, 4: 40-51.

Chen, et. al. 2017. Divide, Share, and Conquer: Multi-task Attribute Learning with Selective Sharing. F, R. et al. (ed). Visual attributes. Cham: Springer. 50-85.

Del Bimbo, A.1999. Visual information retrieval. San Francisco: Morgan Kaufmann.

Deledalle, G. 1979. Théorie et pratique du signe. Paris: Payot.

DeLoache, J. 2004. Becoming Symbol-Minded. Trends in Cognitive Sciences, 8(2). 66-70.

Eco, U. 1976. A theory of semiotics. Bloomington: Indiana University Press.

Floch, J-M. 1978. Roland Barthes: "Sémiotique de l'image", Bulletin du Groupe de Recherches Sémio-linguistiques, 4/5, 27-32.

Floch, J-M. 1981. Kandinsky: sémiotique d'un discours plastique non-figuratif. 
Communications, 34, 134-158.

Floch, J-M. 1984. Petites mythologies de l'oeil et l'esprit. Paris: Hadès.

Floch, J-M. 1986a. Les formes de l'empreinte. Périgueux: Pierre Fanlac.

Floch, J-M. 1986b. Paraître/s'afficher, analyse sémiotique de quelques campagnes d'affichage de presse quotidienne. Affiches de pub. Paris: Editions du Chêne.

Floch, J-M. 1990. Sémiotique, marketing et communication. Paris: PUF.

Gonzalez R., \& Woods R. 2008. Digital Image Processing. Upper Saddle River: Pearson.

Greimas, A. \& J. Courtés. 1979. Sémiotique. Dictionnaire raisonné de la théorie du langage.

Paris: Hachette.

Groupe $\mu$. 1992. Traité du signe visuel. Paris: Seuil.

Groys, B. 2016. In the flow. London: Verso.

Hribar, A., Sonesson, G. \& Call, J. 2014. From sign to action. Studies in chimpanzee pictorial competence. Semiotica, 198, 205-240.

Kirsch, J. \& Kirsch, R. 1988. The anatomy of painting style: description with computer rules. Leonardo. 21/4, 437-444.

Jappy, T. 2010. Introduction to Peircean Visual Semiotics. London: Bloomsbury.

Krampen, M. (ed.). 1983. Visuelle Kommunikation und/oder verbale Kommunikation. Hildesheim \& Berlin: Olms Verlag/Hochschule der Kiinste.

Lenninger, S. 2012. When Similarity Qualifies as a Sign : A Study in Picture Understanding and Semiotic Development in Young Children. Lund University. Dissertation.

Lindekens, R. 1976. Éléments de sémiotique visuelle. Paris: Klincksieck.

Manovich, L. 2011. What is visualization? Visual studies. 26/1, 36-49.

Müller, W., Nocke, T., Schumann, H. 2006. Enhancing the Visualization Process with Principal Component Analysis to Support the Exploration of Trends, Asia-Pacific Symposium on Information Visualization (APVIS'06). pp. 121-130.

Parker, J.R. 2011. s. Indianapolis: Wiley.

Reyes, E. 2017. The image-interface: graphical supports for visual information. London: Wiley-ISTE.

Russ, J. 2011. The image processing handbook. Boca Raton: CRC.

Sebeok, T. \& M. Danesi. Berlin; New York : De Gruyter Mouton.

Sonesson, G. 1988. Methods and models in pictorial semiotics. Lund: Lund University.

Sonesson, G. 1989a. Pictorial concepts. Lund: Lund University Press.

Sonesson, G. 1989b. Semiotics of photography. On tracing the index. Lund: Lund University.

Sonesson, G. 1994. Les rondeurs secrètes de la ligne droite. A propos de "Sans titre" de Rothko. Les Nouveaux Actes Sémiotiques. 41-76.

Sonesson, G. 2004. Rhétorique du monde de la vie. Hénault, A. \& A. Beyaert (eds). Ateliers de sémiotique visuelle. 83-100. Paris: PUF.

Sonesson, G. 2008. Beyond methods and models. Semiotics as a distinctive discipline and an intellectual tradition. Signs - International Journal of Semiotics. 277-319.

Sonesson, G. 2010. Pictorial semiotics in Encyclopedic dictionary of semiotics, edited by

Sonesson, G. 2011. La rhétorique des transformations homogènes. Migliore, T. (ed.). Retorica del visibili. 309-320. Rome: Aracne.

Sonesson, G. 2012. Semiotics inside-out and/or outside-in: How to understand everything and (with luck) influence people. Signata. 2. 315-348.

Sonesson, G. 2013. Aspects of 'physiognomic depiction' in pictures. From macchia to microgenesis. In Culture \& Psychology 19, 4: Special issue on Werner and Kaplan's Symbol formation. 533-547.

Sonesson, G. 2014. The psychology and semiotics of the picture sign. Machin, D. (ed). Handbook of Visual communication. 23-50. Berlin: DeGuyter.

Sonesson, G. 2015. Signs and Gestalten. From Visual Thinking to Pictorial Concepts. In, 
Gestalt Theory, 37, 3, 257-272

Sonesson, G. \& S. Lenninger. (2015). The psychological development of semiotic competence: from the window to the movie by way of the mirror. Cognitive Development, 36, 191-201.

Thürleman, F. 1982. Paul Klee. Analyse sémiotique de trois peintures. Lausanne: L'age de l'homme.

Thürleman, F. 1990. Vom Bild zum Raum. Köln: DuMont.

Zlatev, J, Madsen, A., Lenninger, S., Persson, T., Sayehli, S., Sonesson, G., \& van de Weijer, J. 2013. Understanding communicative intentions and semiotic vehicles by children and chimpanzees. Cognitive Development, 28: 312-329. 